\title{
Comparative Study of Different Cross-Linking Agents for the Immobilization of Functionalized Carbon Nanotubes within a Chitosan Film Supported on a Graphite-Epoxy Composite Electrode
}

\author{
Rasa Pauliukaite, ${ }^{\dagger}$ Mariana Emilia Ghica, ${ }^{\dagger}$ Orlando Fatibello-Filho, ${ }^{\dagger, *}$ and \\ Christopher M. A. Brett*,t
}

Departamento de Química, Faculdade de Ciências e Tecnologia, Universidade de Coimbra, 3004-535 Coimbra, Portugal, and Departamento de Química, Universidade Federal de São Carlos, C.P. 676, 13560-970 São Carlos-SP, Brazil

The effectiveness of immobilization of functionalized carbon nanotubes into chitosan using different crosslinking agents has been evaluated. The cross-linkers used were glyoxal (GO), glutaraldehyde (GA), epichlorohydrin (ECH), and 1-ethyl-3-(3-dimethylaminopropyl) carbodiimide together with $\mathrm{N}$-hydroxysuccinimide (EDC-NHS), and the nanotubes were retained on graphite epoxy resin composite electrodes. The nanotube modified electrodes have been characterized by cyclic voltammetry (CV) and electrochemical impedance spectroscopy (EIS). Using CV and EIS in the presence of potassium hexacyanoferrate(III), the electroactive area of all types of electrodes was determined and the redox process analyzed, leading to the conclusion that ECH and EDC-NHS are better for immobilization of functionalized carbon nanotubes inside the chitosan matrix. The modified electrodes were successfully applied to the determination of hydrogen peroxide by fixed potential amperometry at $-0.1 \mathrm{~V}$ vs SCE, the highest response being exhibited when using ECH.

Carbon nanotubes (CNTs) have received great attention since they were discovered in 1991 by Iijima. ${ }^{1}$ As is well-known, there are two groups of CNTs, single-wall carbon nanotubes (SWCNTs) and multiwall carbon nanotubes (MWCNTs). The first consist of a single sheet of graphene rolled seamlessly, defining a cylinder of 1-2 nm diameter, and MWCNTs can be visualized as several concentric tubes of graphene inside one another with diameters

\footnotetext{
* To whom correspondence should be addressed. Phone/fax: +351239835295 . E-mail: brett@ci.uc.pt.

$\dagger$ Universidade de Coimbra.

* Universidade Federal de São Carlos.

(1) Iijima, S. Nature 1991, 354, 56-58.

(2) Merkoçi, A.; Pumera, M.; Llopis, X.; Pérez, B.; del Valle, M.; Alegret, S. Trends Anal. Chem. 2005, 24, 826-838.

(3) Valentini, F.; Amine, A.; Orlanducci, S.; Terranova, M. L.; Palleschi, G. Anal. Chem. 2003, 75, 5413-5421.

(4) Rivas, G. A.; Rubianes, M. D.; Rodríguez, M. C.; Ferreyra, N. F.; Luque, G. L.; Pedano, M. L.; Miscoria, S. A.; Parrado, C. Talanta 2007, 74, 291307.

(5) Agüí, L.; Yáñez-Sedeño, P.; Pingarrón, J. M. Anal. Chim. Acta 2008, 622, $11-47$.
}

typically ranging from 2 to $100 \mathrm{~nm}$, separated by a distance of $0.3-0.4 \mathrm{~nm} .^{2-6}$

Because of their unique structure, mechanical strength, and electronic properties, CNTs are attractive materials for a wide range of applications. ${ }^{2-13}$ In electroanalytical chemistry, CNTs are used as electrode modifiers in order to decrease the overpotential and/or increase the rate of reaction of various electroactive substrates, ${ }^{3,4}$ showing better electrochemical performance than conventional carbon electrodes. ${ }^{3,10}$ There have been several reports which show that the electroactivity of CNTs is due to the presence of reactive groups on their surface and/or defect-areas of the nanotubes. ${ }^{6-8}$ A number of authors ${ }^{2-6}$ have considered the advantages of using CNTs for electrode surface modification in the development of new designs of electrochemical sensors and biosensors. There are different methods to prepare, solubilize, and modify electrodes with $\mathrm{CNTs}^{2-6}$

The insolubility of CNTs in all solvents can be a major drawback to their use as modifiers in electrodes, and several strategies have been proposed to disperse them, such as end and sidewall functionalization, ${ }^{6,14,15}$ use of surfactants with sonication, ${ }^{16}$ polymer wrapping, ${ }^{17}$ and covalent binding. ${ }^{2}$

(6) Wildgoose, G. G.; Banks, C. E.; Leventis, H. C.; Compton, R. G. Microchim. Acta 2006, 152, 187-214.

(7) Banks, C. E.; Compton, R. G. Analyst 2005, 130, 1232-1239.

(8) Banks, C. E.; Compton, R. G. Analyst 2006, 131, 15-21.

(9) Gouveia-Caridade, C.; Pauliukaite, R.; Brett, C. M. A. Electrochim. Acta 2008, 53, 6732-6739.

(10) Wang, J. X.; Li, M. X.; Shi, Z. J.; Li, N. Q.; Gu, Z. N. Anal. Chem. 2002, 74, 1993-1997.

(11) Zhao, G. C.; Yin, Z. Z.; Zhang, L.; Wei, X. W. Electrochem. Commun. 2005, 7, 256-260.

(12) Yin, Y. J.; Wu, P.; Lu, Y. F.; Du, P.; Shi, Y. M.; Cai, C. X. J. Solid State Electrochem. 2007, 11, 390-397.

(13) Zhao, Q.; Gan, Z. H.; Khuang, Q. K. Electroanalysis 2002, 14, 1609-1613.

(14) Saini, R. K.; Chiang, I. W.; Peng, H. Q.; Smalley, R. E.; Billups, W. E.; Hauge, R. H.; Margrave, J. L. J. Am. Chem. Soc. 2003, 125, 3617-3621.

(15) Chen, J.; Hamon, M. A.; Hu, H.; Chen, Y.; Rao, A. M.; Eklund, P. C.; Haadon, R. C. Science 1998, 282, 95-98.

(16) Islam, M. F.; Rojas, E.; Bergey, D. M.; Johnson, A. T.; Yodh, A. G. Nano Lett. 2003, 3, 269-273.

(17) Star, A.; Stoddart, J. F.; Steuerman, D.; Diehl, M.; Boukai, A.; Wong, E. W.; Yang, X.; Chung, S. W.; Choi, H.; Heath, J. R. Angew Chem., Int. Ed. 2001, $40,1721-1725$. 


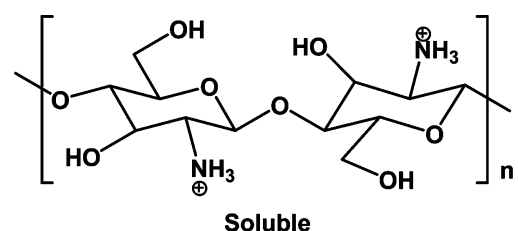

Soluble

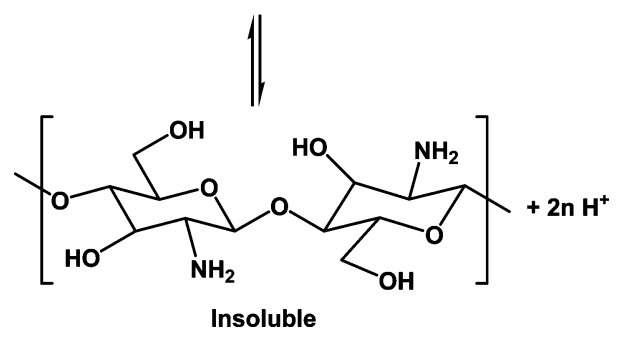

Figure 1. Chemical equilibrium of chitosan in solution.

The use of chitosan as a matrix offers numerous advantages, as will be discussed below. Chitosan is a linear $\beta-1,4$-linked polysaccharide (similar to cellulose) that is obtained by the partial deacetylation of chitin, a major component of the shells of crustaceans such as crab, shrimp, and crawfish. Since chitin deacetylation is incomplete, chitosan is formally a copolymer composed of glucosamine and $\mathrm{N}$-acetylglucosamine. Chitosan possesses distinct chemical and biological properties, ${ }^{18}$ due to the fact that it has reactive amino and hydroxyl groups in its linear polyglucosamine high molar mass chains and which are amenable to chemical modification. ${ }^{18-22}$ Additionally, amino groups make chitosan a cationic polyelectrolyte $\left(\mathrm{p} K_{\mathrm{a}} \cong 6.5\right)$, one of the few found in nature. Its basicity gives chitosan unique properties; it is soluble in aqueous acidic media at $\mathrm{pH}$ lower than 6.5 and, when dissolved, possesses a high positive charge due to the $-\mathrm{NH}_{3}{ }^{+}$groups (see Figure 1); therefore, it can easily adhere to negatively charged surfaces and aggregate with polyanionic compounds as well as chelate various metal cations. Besides its good adhesion, chitosan has a high permeability toward water and a number of anions and cations, a high mechanical strength, an excellent film-forming ability, and finally, it is a very good matrix for enzyme and/or biomacromolecule immobilization. ${ }^{18}$

Methods for chitosan film preparation described in the literature $^{23}$ can be broadly divided into four groups, namely: solvent evaporation, neutralization, cross-linking, and ionotropic gelation methods.

In this article, the effectiveness of four different cross-linking agents: glyoxal (GO), glutaraldehyde (GA), epichlorohydrin $(\mathrm{ECH})$, and 1-ethyl-3-(3-dimethylaminopropyl) carbodiimide/ $\mathrm{N}$ hydroxysuccinimide (EDC-NHS) have been evaluated for casting chitosan films and for the immobilization of functionalized multiwall carbon nanotubes (MWCNTs) on the top of graphite-epoxy composite electrodes. Chitosan polymer film was deposited on the composite electrode surface by drop-coating of the protonated polymer solution with or without MWCNT onto the electrode

(18) Yi, H.; Wu, L.-Q.; Bentley, W. E.; Ghodss, R.; Rubloff, G. W.; Culver, J. N.; Payne, G. F. Biomacromolecules 2005, 6, 2881-2894.

(19) de Oliveira, I. R. W. Z.; Vieira, I. C. Enzyme Microb. Technol. 2006, 38, 449-456.

(20) Wan, Y.; Creber, K. A. M.; Peppley, B.; Bui, V. T. Polymer 2003, 44, 10571065.

(21) Deng, Y.; Liu, D.; Du, G.; Li, X.; Chen, J. Polym. Int. 2007, 56, 738-745.

(22) Cruz, J.; Kawasaki, M.; Gorski, W. Anal. Chem. 2000, 72, 680-686.

(23) Krajewska, B. Enzyme Microb. Technol. 2004, 35, 126-139. surface. The resulting electrodes modified with carbon nanotubes and different cross-linkers have been characterized by cyclic voltammetry and electrochemical impedance spectroscopy. The suitability of the electrodes has been tested by applying them to the determination of hydrogen peroxide by fixed potential amperometry at potentials close to zero.

\section{EXPERIMENTAL SECTION}

Apparatus. Cyclic voltammetry and chronoamperometry were performed using a Palm Sense potentiostat from Palm Instruments BV (The Netherlands) running with PS Lite 1.7.3 software. Electrochemical impedance measurements were carried out using a Solartron 1250 frequency response analyzer, coupled to a Solartron 1286 electrochemical interface (U.K.) controlled by ZPlot software. The frequency range used was $65 \mathrm{kHz}$ to $0.1 \mathrm{~Hz}$ with 10 frequencies per decade and integration time $60 \mathrm{~s}$. The $\mathrm{pH}$ measurements were done with a CRISON 2001 micro pH-meter (Spain). All experiments were performed at room temperature, $25 \pm 1{ }^{\circ} \mathrm{C}$.

Chemicals. Multiwalled carbon nanotubes (MWCNTs) were obtained from NanoLab. Araldit epoxy resin and Araldit hardener were purchased from Ceys S.A. (Spain). Graphite powder (grade no. 38) was obtained from Fisher Scientific Corporation. Glyoxal (GO) (40\% v/v solution), epichlorohydrin (ECH) (99\% v/v solution), and chitosan (Chit) of low molecular weight with a degree of deacetylation of $80 \%$ were obtained from Aldrich (Germany). Glutaraldehyde (GA) (25\% v/v solution) and 1-ethyl-3-(3-dimethylaminopropyl) carbodiimide (EDC) were purchased from Sigma (Germany) and $N$-hydroxysuccinimide (NHS) was from Fluka (Germany). Potassium hexacyanoferate(III) was acquired from Merck (Germany) and potassium chloride was from Fluka (Germany). Millipore Milli-Q nanopure water (resistivity >18 M $\Omega$ $\mathrm{cm}$ ) was used for preparation of all solutions.

Pretreatment of Multiwalled Carbon Nanotubes. Multiwalled carbon nanotubes (MWCNT) were purified and functionalized as described elsewhere. ${ }^{9}$ A mass of $120 \mathrm{mg}$ of MWCNT was stirred in $10 \mathrm{~mL}$ of a $3 \mathrm{M}$ nitric acid solution for $20 \mathrm{~h}$. The solid product was collected on a filter paper and washed several times with nanopure water until the filtrate solution became neutral $(\mathrm{pH} \cong 7)$. The functionalized MWCNTs obtained were then dried in an oven at $80{ }^{\circ} \mathrm{C}$ for $24 \mathrm{~h}$. Nitric acid usually causes significant destruction of carbon nanotubes and introduces $-\mathrm{COOH}$ groups at the ends or at the sidewall defects of the nanotube structure.

Preparation of Graphite-Epoxy Composite Electrode. Graphite-epoxy composite electrodes were used as electrode substrates. These were prepared using graphite powder and Araldit epoxy resin/hardener by hand-mixing in the ratio 70:30 $(\mathrm{m} / \mathrm{m})$ as described previously. ${ }^{24}$ The resulting paste was placed into the tip of a $1 \mathrm{~mL}$ insulin plastic syringe, and a copper rod with diameter equal to the inner size of the syringe was inserted to give the external electrical contact. Before each use, the surface of the composite electrode was wetted with Milli $\mathrm{Q}$ water and then thoroughly smoothed, first with abrasive paper and then with polishing paper, Kemet (U.K.).

(24) Fagury, R. L. R. P.; Lupetti, K. O.; Fatibello-Filho, O. Anal. Lett. 2005, 38, 1857-1867. 
Table 1. Slopes of the Peak Current Dependence on Square Root of the Scan Rate, of the Peak Potential Dependence on Logarithm of the Scan Rate, and Electroactive Area of Different Electrodes ${ }^{a}$

\begin{tabular}{|c|c|c|c|c|c|c|}
\hline film composition & $\begin{array}{c}j_{\mathrm{p}}^{\mathrm{ox}} \mathrm{vs} v^{1 / 2} / \\
\mu \mathrm{A} \mathrm{cm}{ }^{-2} \mathrm{mV}^{1 / 2} \mathrm{~s}^{-1 / 2}\end{array}$ & $\begin{array}{c}j_{\mathrm{p}}^{\mathrm{red}} \mathrm{vs} v^{1 / 2} / \\
\mu \mathrm{A} \mathrm{cm}{ }^{-2} \mathrm{mV}^{1 / 2} \mathrm{~s}^{-1 / 2}\end{array}$ & $\begin{array}{c}E_{\mathrm{p}}^{\mathrm{ox}} / \\
\log \left(v / \mathrm{V} \mathrm{s}^{-1}\right) / \mathrm{V} \mathrm{dec}^{-1}\end{array}$ & $\begin{array}{c}E_{\mathrm{p}}^{\mathrm{red}} / \\
\log \left(v / \mathrm{V} \mathrm{s}^{-1}\right) / \mathrm{V} \mathrm{dec}^{-1}\end{array}$ & $\begin{array}{l}A_{\mathrm{EA}}, / \\
\mathrm{cm}^{2}\end{array}$ & $\begin{array}{c}C / \\
\mathrm{mF} \mathrm{cm} \mathrm{cm}^{-2}\end{array}$ \\
\hline Chit-GO & $0.58 \pm 0.04$ & $-0.63 \pm 0.05$ & $0.062 \pm 0.001$ & $-0.063 \pm 0.003$ & 0.073 & 1.46 \\
\hline Chit-GO-MWCNT & $0.25 \pm 0.05$ & $-0.29 \pm 0.03$ & $0.041 \pm 0.003$ & $-0.067 \pm 0.003$ & 0.031 & 1.23 \\
\hline Chit-GA-MWCNT & $2.13 \pm 0.40$ & $-3.63 \pm 0.04$ & $0.19 \pm 0.02$ & $-0.20 \pm 0.02$ & 0.229 & 9.33 \\
\hline Chit-ECH & $0.69 \pm 0.04$ & $-0.75 \pm 0.04$ & $0.051 \pm 0.004$ & $-0.046 \pm 0.003$ & 0.057 & 1.72 \\
\hline Chit-ECH-MWCNT & $1.69 \pm 0.12$ & $-2.06 \pm 0.04$ & $0.089 \pm 0.001$ & $-0.099 \pm 0.002$ & 0.150 & 12.3 \\
\hline Chit-EDC-NHS & $1.31 \pm 0.04$ & $-1.56 \pm 0.12$ & $0.051 \pm 0.004$ & $-0.044 \pm 0.002$ & 0.123 & 2.26 \\
\hline
\end{tabular}

${ }^{a}$ Geometric area $0.196 \mathrm{~cm}^{2}$, data from cyclic voltammograms of hexacyanoferrate(III) in $0.1 \mathrm{M} \mathrm{KCl}$, conditions as in Figure 4 . Capacitance values (last column) from cyclic voltammograms in $0.1 \mathrm{M} \mathrm{KCl}$ electrolyte solution.

Preparation of the Film Electrodes Containing Functionalized MWCNTs. A $1.0 \% \mathrm{~m} / \mathrm{m}$ chitosan (Chit) stock solution was prepared by dissolving $100 \mathrm{mg}$ of Chit powder in $10 \mathrm{~mL}$ of $1.0 \%$ $\mathrm{v} / \mathrm{v}$ acetic acid solution and stirred for $3 \mathrm{~h}$ at room temperature until complete dissolution occurred. The Chit solution was stored under refrigeration at $4{ }^{\circ} \mathrm{C}$ when not in use.

A dispersion of $1.0 \% \mathrm{~m} / \mathrm{v}$ functionalized MWCNTs in $1.0 \% \mathrm{~m} / \mathrm{m}$ chitosan was prepared by sonication of $2 \mathrm{mg}$ of functionalized MWCNTs in $200 \mu \mathrm{L}$ of $1.0 \% \mathrm{~m} / \mathrm{m}$ Chit in $1.0 \% \mathrm{v} / \mathrm{v}$ acetic acid solution for $2 \mathrm{~h}$.

All chitosan-containing films were obtained using either $1.0 \%$ $\mathrm{m} / \mathrm{m}$ Chit solution or $1.0 \% \mathrm{~m} / \mathrm{v}$ functionalized MWCNTs in $1.0 \%$ $\mathrm{m} / \mathrm{m}$ chitosan together with one of (a) glyoxal, (b) glutaraldehyde, (c) epichlorohydrin, or (d) 1-ethyl-3-(3-dimethylaminopropyl) carbodiimide/ $N$-hydroxysuccinimide as cross-linkers, placed directly onto the graphite-epoxy composite electrode.

The graphite-epoxy composite electrode was covered, in all cases, by first dropping $10 \mu \mathrm{L}$ of $1 \% \mathrm{~m} / \mathrm{m}$ Chit or $10 \mu \mathrm{L}$ of $1 \% \mathrm{~m} / \mathrm{v}$ MWCNTs in $1.0 \% \mathrm{~m} / \mathrm{m}$ Chit and leaving it to dry for $1 \mathrm{~h}$. After solvent evaporation, a second aliquot of $10 \mu \mathrm{L}$ of Chit or MWCNT/ Chit dispersion was dropped on the surface and the coated electrode was again left for solvent evaporation at room temperature in air for approximately $1 \mathrm{~h}$. Then, $10 \mu \mathrm{L}$ of $0.02 \mathrm{M} \mathrm{NaOH}$ solution was placed on the surface and dried for $40 \mathrm{~min}$, followed by another aliquot of the same reagent, the purpose being to deprotonate the amino groups of Chit by changing the $\mathrm{pH}$ at the electrode surface. In the case of the EDC/NHS cross-linker, this procedure with $\mathrm{NaOH}$ solution was performed only once in order not to increase the $\mathrm{pH}$ too much.

After this, the cross-linker was incorporated by using one of the following procedures: (a) For glyoxal, after rinsing with abundant nanopure water, $10 \mu \mathrm{L}$ of $0.1 \mathrm{M}$ phosphate buffer solution at $\mathrm{pH} 7.0$ was placed on the surface and the electrode was left to dry. Finally, $10 \mu \mathrm{L}$ of $2.0 \% \mathrm{v} / \mathrm{v}$ of GO solution was dropped on the top of the electrode and left to dry for $1 \mathrm{~h}$. (b) For glutaraldehyde, the electrode was treated in to the same way as for glyoxal, except that the GO solution was replaced by a $2.5 \%$ v/v GA solution. (c) For epichlorohydrin, an aliquot of $10 \mu \mathrm{L}$ of $2.5 \% \mathrm{v} / \mathrm{v} \mathrm{ECH}$, adjusted to $\mathrm{pH} 10$ with $0.1 \mathrm{M} \mathrm{NaOH}$ solution, was dropped onto the electrode surface and left to dry for $40 \mathrm{~min}$. Then, a second $10 \mu \mathrm{L}$ aliquot was added and left to dry for $2 \mathrm{~h}$. (d) For 1-ethyl-3-(3-dimethylaminopropyl) carbodiimide/ $N$-hydroxysuccinimide, the electrode was washed thoroughly with $\mathrm{pH}$ 5.5 phosphate buffer solution. Then, $10 \mu \mathrm{L}$ of $0.5 \% \mathrm{~m} / \mathrm{v} \mathrm{EDC} /$
$0.5 \% \mathrm{~m} / \mathrm{v}$ NHS in the same buffer solution was dropped on the surface and left to dry for $2 \mathrm{~h}$. The electroactive area of each electrode was determined experimentally from the cyclic voltammetry of potassium hexacyanoferrate(III), as described elsewhere. $^{25}$

\section{RESULTS AND DISCUSSION}

Electrochemical Characterization of Graphite-Epoxy Composite Electrodes Modified with Carbon Nanotubes. Electrochemical characterization of the graphite-epoxy composite electrodes, unmodified and modified with MWCNT-Chit using different cross-linking agents, was performed using cyclic voltammetry and electrochemical impedance spectroscopy. The data obtained from these measurements were analyzed and compared in order to ascertain the best cross-linking agent for the MWCNT-Chit films. The main parameters obtained from analysis of cyclic voltammograms of hexacyanoferrate(III) as model redox species, in particular the peak current dependence on square root of scan rate for oxidation and reduction, the slope of the potential dependence on logarithm of the scan rate for oxidation and reduction, and the calculated electroactive area and capacitance in electrolyte solution are summarized in Table 1 . The electroactive area was calculated, as in ref 25 , from the hexacyanoferrate(III) reduction peaks applying the Randles-Sevcik equation and the diffusion coefficient for $\mathrm{Fe}(\mathrm{CN})_{6}{ }^{3-}$ in $0.1 \mathrm{M} \mathrm{KCl}$ solution of $6.2 \times 10^{-6} \mathrm{~cm}^{2} \mathrm{~s}^{-1} \cdot 26$

Cyclic Voltammetry. Characterization of Chitosan Film Electrodes Cross-Linked with Glyoxal. Glyoxal (OCHCHO) is a small reactive molecule, the shortest dialdehyde, and is able to act as a cross-linking agent. Its possible cross-linking mechanism is shown in Figure 2. GO binds $-\mathrm{NH}_{2}$ groups from different Chit chains and so covalently cross-links Chit molecules, forming a polymer network with the formation of two Schiff bases involving both the aldehyde groups of GO. ${ }^{27}$ Functionalized MWCNT (possessing - $\mathrm{COOH}$ groups) can be electrostatically bonded to the other free $-\mathrm{NH}_{2}$ groups from Chit, in this way retaining the MWCNT on the Chit attached to the electrode surface. Thus, as more $\mathrm{GO}$ is added, more chitosan $-\mathrm{NH}_{2}$ groups are cross-

(25) Gooding, J. J.; Praig, V. G.; Hall, E. A. H. Anal. Chem. 1998, 70, 23962402.

(26) Barsan, M. M.; Pinto, E. M.; Florescu, M.; Brett, C. M. A. Anal. Chim. Acta 2009, 635, 71-78.

(27) Monteiro, O. A. C., Jr.; Airoldi, C. J. Colloid Interface Sci. 2005, 282, 3237.

Analytical Chemistry, Vol. xxx, No. xx, Month XX, XXXX 

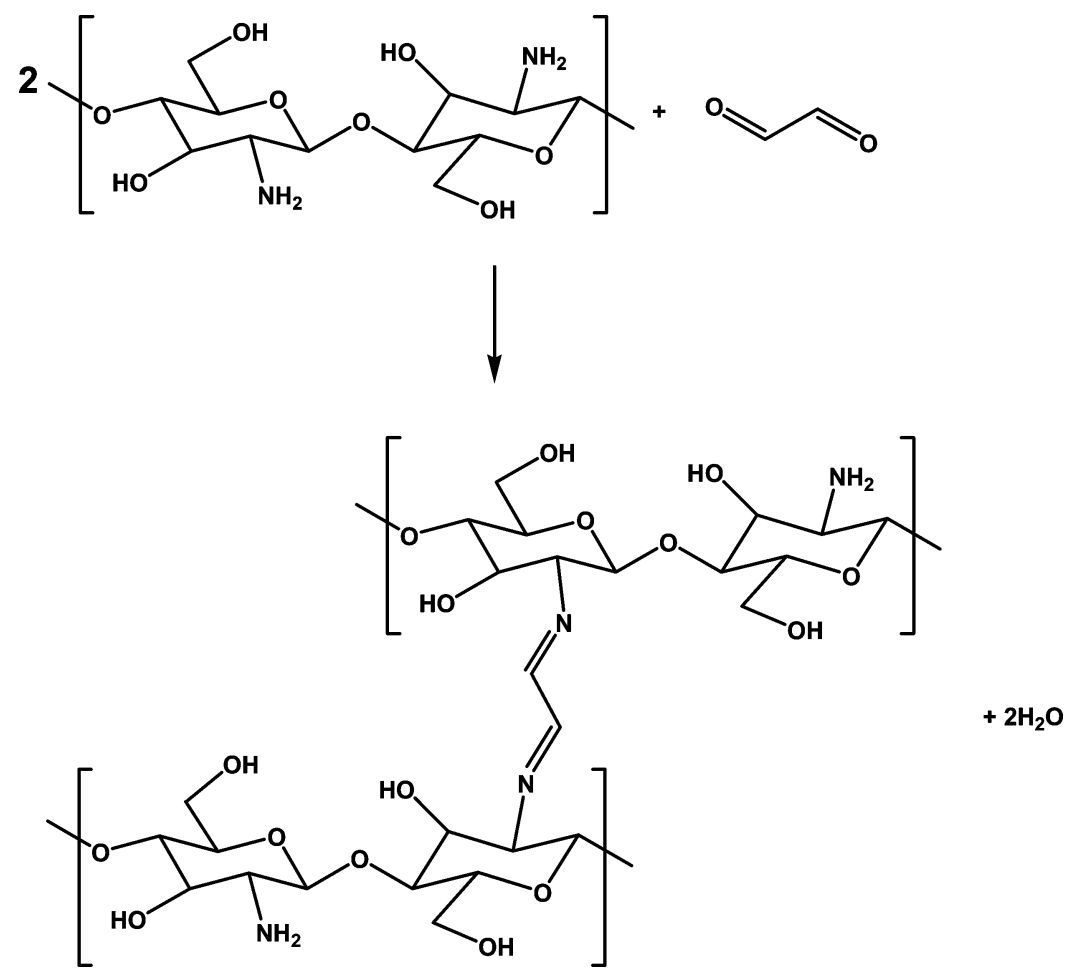

Figure 2. Possible mechanism of Chit cross-linking with GO.

linked and less are available for interaction with MWCNT, so that CNTs would be more easily washed away from the electrode surface.

Figure 3a shows CVs recorded in $0.1 \mathrm{M} \mathrm{KCl}$ at Chit-GO and Chit-GO-MWCNT. CVs at bare graphite-epoxy composite electrodes were also recorded in order to compare the capacitive current with and without modification. As seen from the CVs, the capacitive currentincreased after modification of the graphite-epoxy composite electrode with Chit-GO. Surprisingly, the changes in current after further electrode modification with MWCNTs were only in the negative potential region. These results show that the electroactive area of the Chit-GO modified electrode increases due to electroactive groups, most probably $-\mathrm{NH}_{2}$, available from chitosan. However, immobilization of MWCNTs showed almost no further change in electroactive area or capacitance. This can be explained through either blocking of the electroactivity of MWCNTs by the polymer film, which is more compact after cross-linking with the short chain GO, and by partial washing of the nanotubes from the electrode surface.

The electroactive area (Table 1) was determined from the peak current obtained in $3 \mathrm{mM} \mathrm{Fe}(\mathrm{CN})_{6}{ }^{3-}$ solution in $0.1 \mathrm{M} \mathrm{KCl}$ electrolyte (Figure 3). Both types of GO cross-linked electrode, with and without CNT, exhibited diffusion-controlled quasireversible behavior observed from the current dependence on the square root of the scan rate (Table 1). With the use of GO as a cross-linking agent, without CNT, the redox peaks were wellshaped (Figure $4 \mathrm{a}$ ) and the peak current increased linearly with the square root of the scan rate with a slope of $\sim 0.14 \mu \mathrm{A} \mathrm{mV} V^{1 / 2}$ $\mathrm{s}^{-1 / 2}$ (Table 1). However, when MWCNTs with Chit-GO were cast on the electrode, the redox peaks became misshapen as seen in Figure 4b, and the slope of the peak current dependence is lower with the MWCNT-modified electrode than without (Table
1), although the peak current is higher than at the electrode without CNTs. The electroactive area was found to be lower with MWCNT than without, which can be explained by just a few $-\mathrm{NH}_{2}$ groups from chitosan being available for interaction with functionalized MWCNT.

Characterization of Chitosan Film Electrodes Cross-Linked with Glutaraldehyde. Glurataldehyde $\left(\mathrm{OCH}\left(\mathrm{CH}_{2}\right)_{3} \mathrm{CHO}\right)$ is one of the most used dialdehyde cross-linking agents for filmelectrode preparation. The cross-linking mechanism is the same as that of GO (Figure 2), the only difference is that the binding dialdehyde chains have three more $-\mathrm{CH}_{2}-$ units.

Electrodes prepared with GA have a different capacitive current profile from GO, as is seen in Figure $3 \mathrm{~b}$. The capacitive current without MWCNT was much lower than with them, which indicated a bigger electroactive area in the presence of MWCNT in the chitosan film. However, the redox response of these electrodes in the presence of $\mathrm{Fe}(\mathrm{CN})_{6}{ }^{3-}$ (not shown) was similar to that of GO: well established redox peaks at the Chit-GA electrode with a rather large peak separation and misshapen peaks at ChitGA-MWCNT, suggesting slow electron transfer kinetics. As with GO, GA-cross-linked films exhibited a linear dependence of the peak current on the square root of the scan rate (Table 1). Unfortunately, the linear range at Chit-GA-MWCNT did not span the whole scan rate range investigated and, in some cases, it was not possible to determine a peak current due to ill-defined peak shapes, especially for reduction, indicating a slow diffusion of the electroactive species through the Chit-GA-MWCNT membrane. This diffusion barrier is probably due to a different polymer membrane structure after cross-linking compared with GO. In the case of GO, MWCNTs were better entrapped physically due to GO's shorter chain, i.e., smaller distance between Chit chains in 

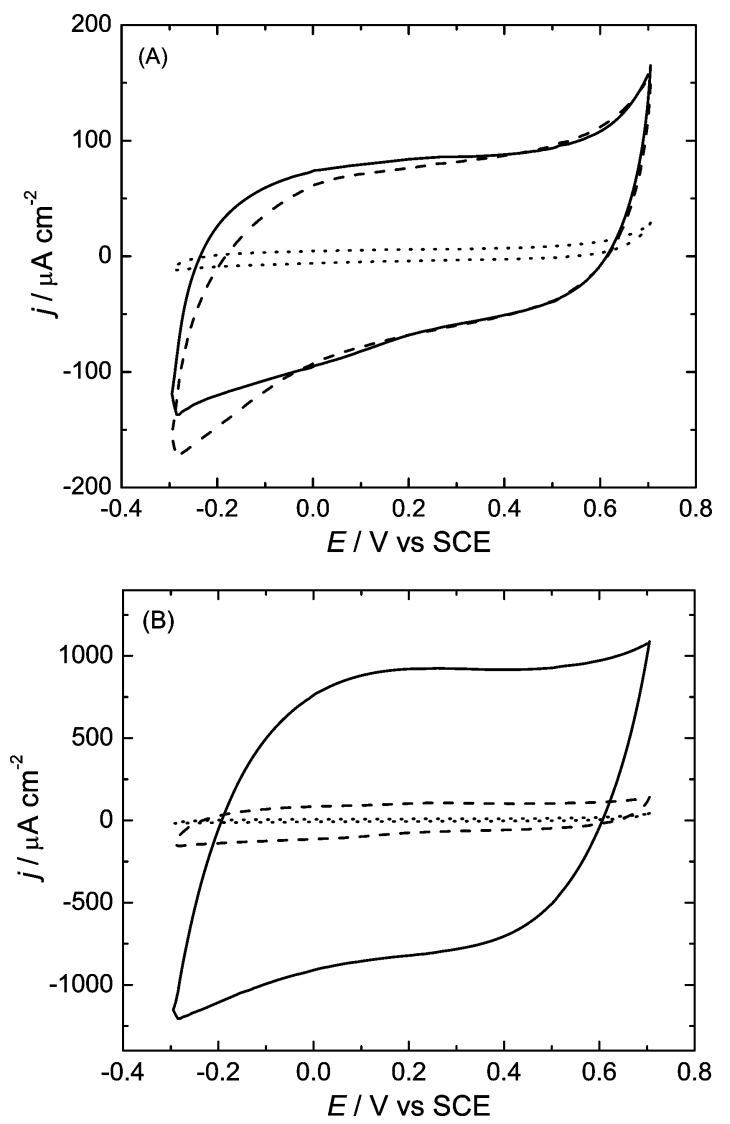

Figure 3. $\mathrm{CVs}$ at the graphite-epoxy composite electrode (dotted line), (A) Chit-GO (dashed line), and Chit-GO-MWCNT (solid line) and (B) Chit-GA (dashed line) and Chit-GA-MWCNT (solid line) in $0.1 \mathrm{M} \mathrm{KCl}$ at scan rate of $50 \mathrm{mV} \mathrm{s}^{-1}$.

comparison with GA as well as double the number of the crosslinking bonds (GO was almost twice the concentration of GA in moles, see Experimental Section). Therefore, there would be larger spaces in the polymer cross-linked with GA.

Characterization of Chitosan Film Electrodes Cross-Linked with Epichlorohydrin. Epichlorohydrin $\left(\mathrm{OCHCH}_{2} \mathrm{CH}_{2} \mathrm{Cl}\right)$ is a short molecule with an epoxy group. This cross-linking agent, contrary to GO and GA, uses the $-\mathrm{OH}$ groups of Chit to covalently bind the chitosan molecules together, shown in Figure 5. As in the previous cases, functionalized CNTs are attached to the polymer surface by electrostatic forces between their $-\mathrm{COOH}$ functional groups and the $-\mathrm{NH}_{2}$ groups from Chit.

The electrochemical investigation of Chit- $\mathrm{ECH}$ and ChitECH-MWCNT modified electrodes by cyclic voltammetry showed almost the same capacitive current profile as in the case of GA. The Chit-ECH-modified electrode had a higher current than the unmodified graphite-epoxy composite, and the Chit-ECH-MWCNT-modified electrode still had a significantly higher capacitive current than that of the Chit-ECH film (not shown but the same tendency as in Figure 3b, see Table 1). The addition of $\mathrm{K}_{3} \mathrm{Fe}(\mathrm{CN})_{6}$ to the electrolyte solution gave a redox response similar to the other electrodes described above. The peak current increased linearly with the square root of the scan rate up to $30 \mathrm{mV} \mathrm{s}^{-1}$ and then became constant (not shown) suggesting that the complete electrode process involves chemical and electrochemical steps. A similar electrochemical behavior was found at the Chit-ECH-
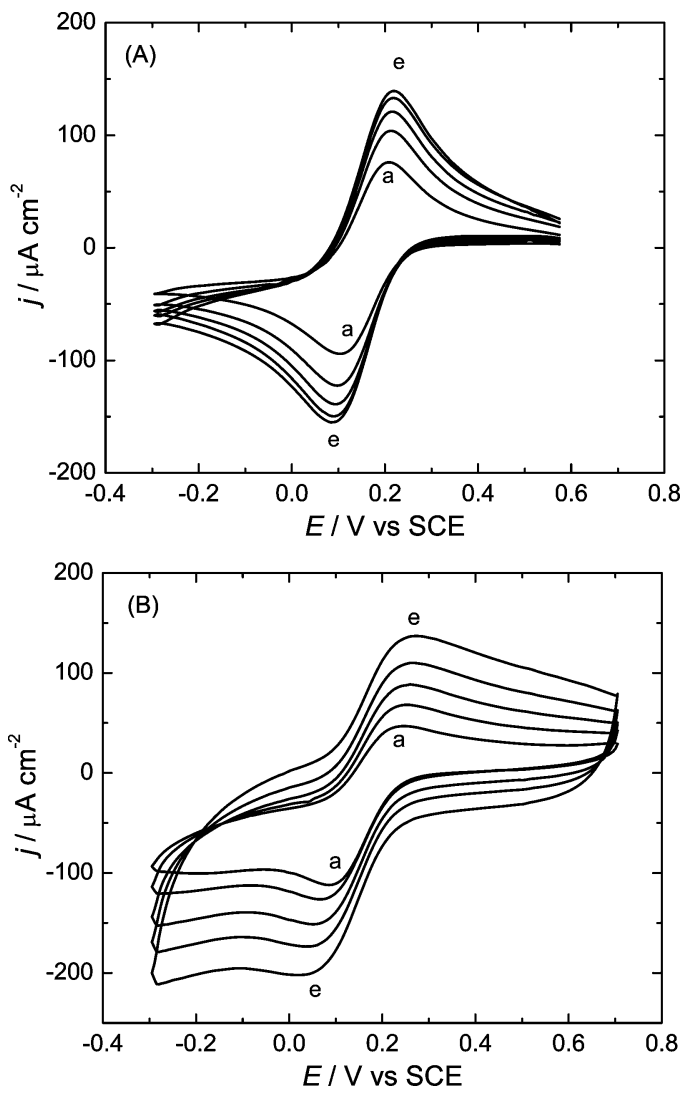

Figure 4. $C V$ s recorded at Chit-GO (A) and Chit-GO-MWCNT (B) film electrode in $3 \mathrm{mM} \mathrm{K}_{3} \mathrm{Fe}(\mathrm{CN})_{6}+0.1 \mathrm{M} \mathrm{KCl}$ at different scan rates $\left(\mathrm{mV} \mathrm{s}^{-1}\right.$ ): (a) 10, (b) 20, (c) 30, (d) 40, and, (e) 50 after background subtraction.

MWCNT-modified electrode. The electroactive area was higher than that of the electrodes with GO and GA, (Table 1 ), and this might be due to more $-\mathrm{NH}_{2}$ groups available for electrostatic interaction with $-\mathrm{COOH}$ groups of MWCNT, since the space between chains of Chit polymer was rather similar to GA and, as discussed above, $\mathrm{ECH}$ uses the $-\mathrm{OH}$ groups of Chit to covalently bind the chitosan chain.

Characterization of Chitosan Film Electrodes CrossLinked with 1-Ethyl-3-(3-Dimethylaminopropyl) Carbodiimide/N-Hydroxysuccinimide. 1-Ethyl-3-(3-dimethylaminopropyl) carbodiimide $\left(\mathrm{C}_{2} \mathrm{H}_{5} \mathrm{NCN}\left(\mathrm{CH}_{2}\right)_{3} \mathrm{NCH}_{3} \mathrm{CH}_{3}\right)$ is an organic carbodiimide, which is usually used with $\mathrm{N}$-hydroxysuccinimide $\left(\mathrm{C}_{5} \mathrm{H}_{2} \mathrm{OONOH}\right)$ for the cross-linking of organic molecules. The cross-linking mechanism of EDC-NHS is different from the others described in this work; EDC and NHS usually act as catalysts for cross-linking reactions and use $-\mathrm{COOH}$ groups for covalent binding to $-\mathrm{NH}_{2}$ in chitosan. A possible scheme is presented in Figure 6. EDC first covalently attaches to the $-\mathrm{COOH}$ groups present on the surface of the graphiteepoxy composite electrode and/or on the ends and side-walls of MWCNTs. These compounds then react with NHS, which substitutes EDC, covalently attaching to the functionalized electrode surface or MWCNTs, releasing 1-(3-(dimethylamino) propyl-3-ethylurea. Furthermore, such structures facilitate Chit reactions in which it substitutes NHS, in this way covalently "gluing" the electrode surface and MWCNTs with 

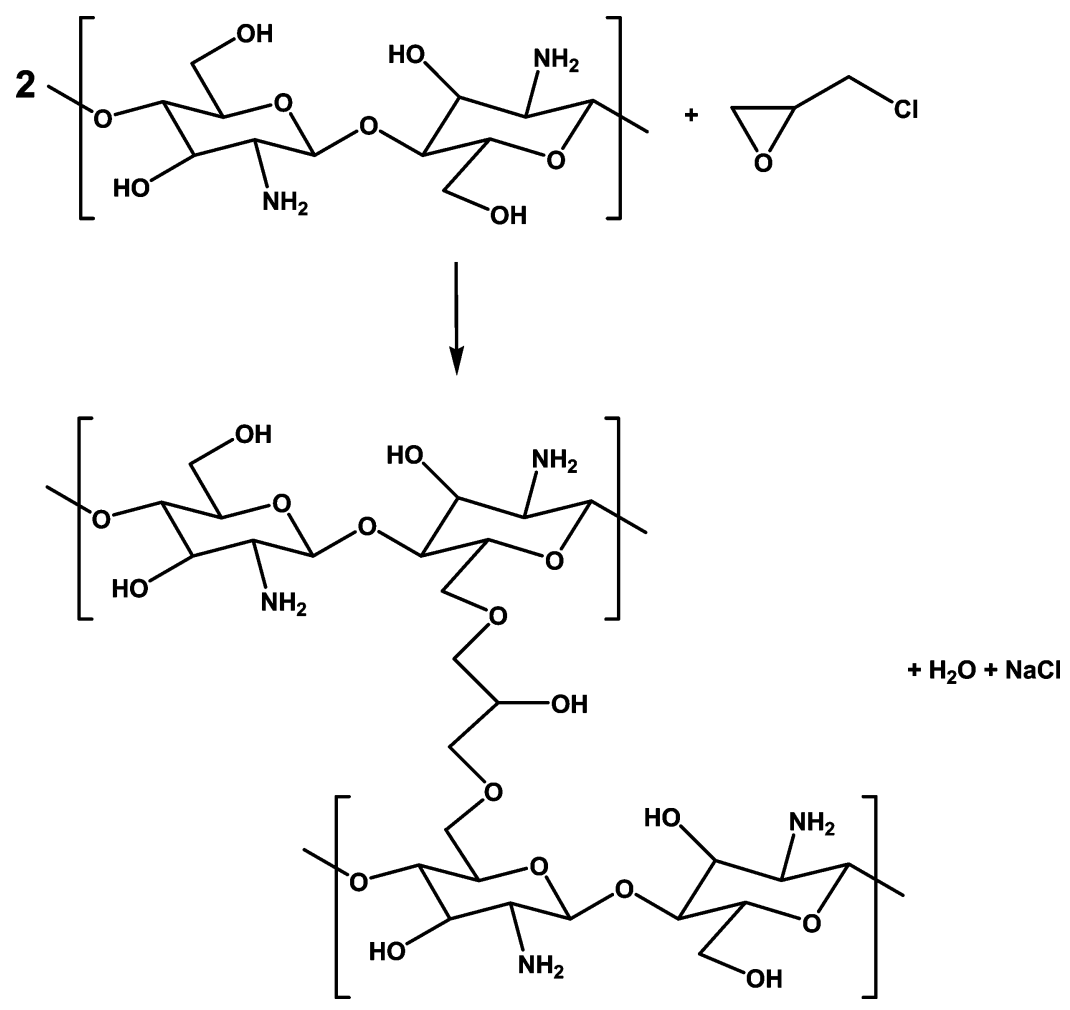

Figure 5. Possible mechanism of Chit cross-linking with $\mathrm{ECH}$.

Chit amino groups releasing unchanged NHS. This method of cross-linking is stronger, since CNTs are also covalently bound to the electrode surface and such electrodes are more stable., ${ }^{58}$

The capacitive current at Chit-EDC-NHS, observed by cyclic voltammetry, see Table 1, was similar to that at Chit-GO, Chit-GA, and Chit-ECH, the only difference being a slightly higher current at Chit-EDC-NHS (about $20 \mu \mathrm{A}$, not shown). After addition of $\mathrm{Fe}(\mathrm{CN})_{6}{ }^{3-}$ to the electrolyte solution, the redox response at the Chit-EDCNHS modified electrode is similar to the other types of modified Chit film studied without CNTs, except that the peak current is 3 times higher (Figure 7a) compared to the Chit electrodes modified with the other three cross-linking agents. This electrode exhibited a linear dependence of the reduction peak current on square root of the scan rate up to $40 \mathrm{mV} \mathrm{s}^{-1}$ with a slope of $\sim-0.25 \mu \mathrm{A} \mathrm{mV} V^{1 / 2}$ $\mathrm{s}^{-1 / 2}$ (Table 1). Although the Chit-EDC-NHS-MWCNT modified electrode had the highest current response compared to all the electrodes studied and the highest capacitance and electroactive area, the electron transfer kinetics was slower since the redox peak separation increased much faster with scan rate. The peak current depends linearly on the square root of the scan rate over the whole scan rate range studied.

Comparison of the Results Obtained by Cyclic Voltammetry. With the use of cyclic voltammetry, it was observed that by immobilizing CNT into chitosan the highest electroactive area was obtained when using EDC-NHS, followed by GA, ECH, and then GO. This behavior is directly paralleled by the capacitance values calculated from cyclic voltammetry in electrolyte solution without redox species. However, in the case of GA, the electron transfer kinetics seems to be much slower, as observed by the dramatically

(28) Wissink, M. J. B.; Beernink, R.; Pieper, J. S.; Poot, A. A.; Engbers, G. H. M.; Beugeling, T.; van Aken, W. G.; Feijen, J. Biomaterials 2001, 22, 151163. increasing peak separation with an increase in scan rate, so this crosslinking agent is not suitable for Chit/MWCNT film formation. GO seems to lead to less good electrochemical behavior on addition of nanotubes as compared with the electrode modified just with Chit; the electroactive area was lower with MWCNT than without (Table 1). ECH showed the best-defined redox peaks and more than a factor of 2 increase in electroactive area with MCWNTs than without them. Thus, it can be concluded that the best cross-linkers for MWCNT immobilization are EDC-NHS and ECH.

Electrochemical Impedance Spectroscopy. Electrochemical impedance spectroscopy was used to shed light on the film features and the electrode-electrolyte interface, in particular with respect to the influence of the different cross-linking agents and of the MWCNT. Impedance spectra were recorded in $3 \mathrm{mM} \mathrm{K} \mathrm{K}_{3} \mathrm{Fe}(\mathrm{CN})_{6}$ in $0.1 \mathrm{M}$ $\mathrm{KCl}$ either at the open circuit potential (OCP), which was in the range $+0.15 \mathrm{~V}$ to $+0.25 \mathrm{~V}$ depending on the cross-linking agent, or at a fixed potential of $+0.15 \mathrm{~V}$ vs SCE. The open circuit potential was close to the midpoint potential from CVs in the case of GA and GO, but it was around $50 \mathrm{mV}$ more positive than the midpoint potential for ECH and EDC-NHS cross-linked CNT-chitosan electrodes. Spectra recorded at OCP and at $+0.15 \mathrm{~V}$ were very similar. The discussion below will focus on spectra recorded at the OCP.

In all cases, the spectra obtained include two regions: a semicircular part at high frequencies corresponding to the electron transfer process and a linear part at lower frequencies corresponding to a diffusion-limited process (Figure 8). For the electrodes without MWCNT, i.e., with only chitosan and cross-linkers, the semicircle is not so well-defined, suggesting that electron transfer is partially blocked by the porous chitosan polymer (see Figure 8b), as was observed previously. ${ }^{29}$ 


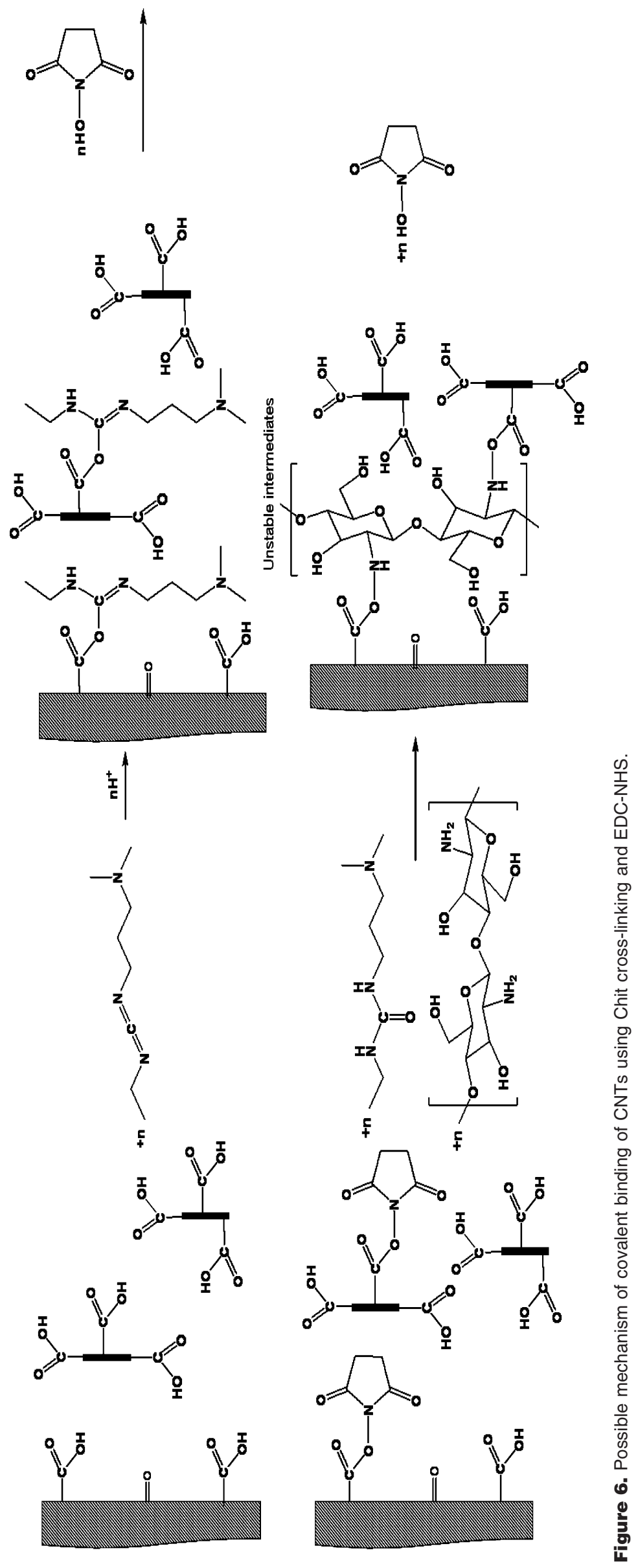

Analytical Chemistry, Vol. xxX, No. $x x$, Month $X X, X X X X \quad \mathrm{G}$ 

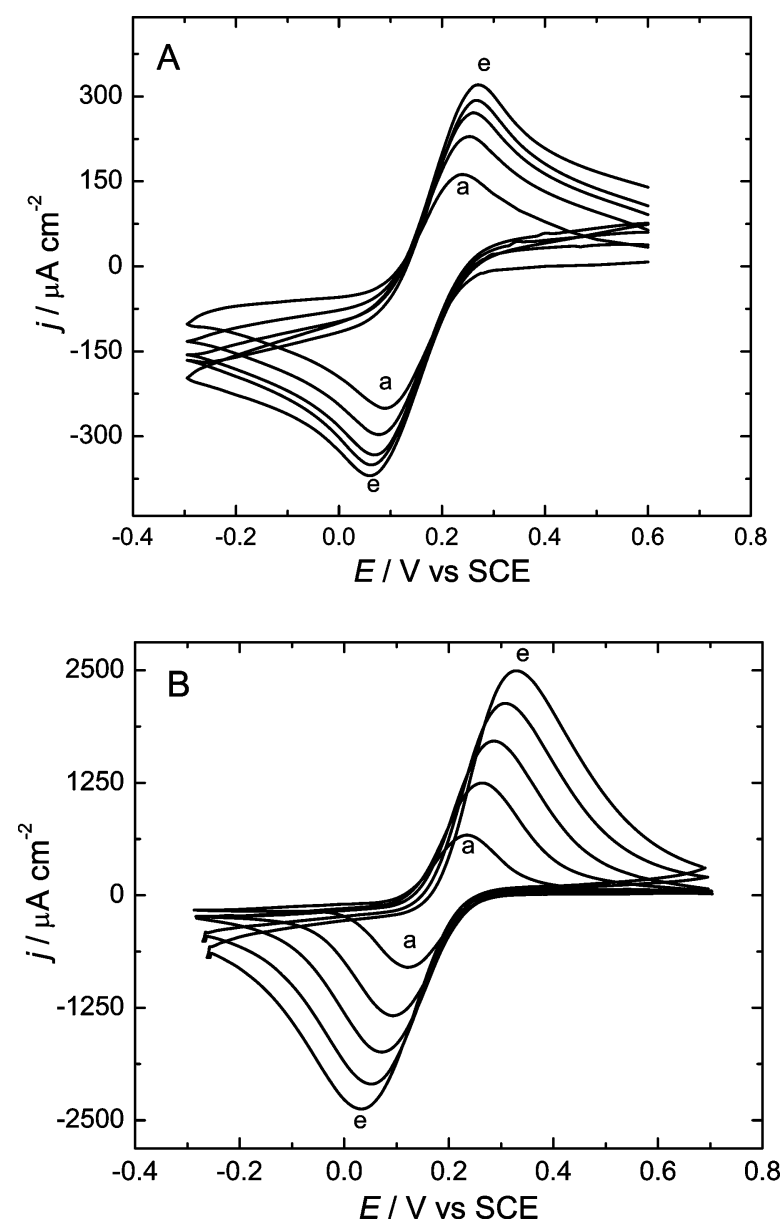

Figure 7. $\mathrm{CVs}$ recorded at Chit-EDC-NHS (A) and Chit-EDC-NHSMWCNT (B) film electrodes in $3 \mathrm{mM} \mathrm{K} \mathrm{K}_{3} \mathrm{Fe}(\mathrm{CN})_{6}+0.1 \mathrm{M} \mathrm{KCl}$ at different scan rates $\left(\mathrm{mV} \mathrm{s}^{-1}\right)$ : (a) 10, (b) 20, (c) 30, (d) 40, and (e) 50 after background subtraction.

All spectra were fitted using the same equivalent electrical circuit containing the cell resistance $R_{\Omega}$ in series with a parallel combination including either a capacitance or, in some cases, a constant phase element (CPE) representing a nonideal capacitance, a charge transfer resistance together with a finite Warburg element, as already used for other CNT-modified electrodes. ${ }^{30}$ The constant phase element was modeled as a nonideal capacitor $\mathrm{CPE}=-1 /$ $(C i \omega)^{n}$, where the capacitance $C$ describes the charge separation at the double layer interface and the $n$ exponent is due to the heterogeneity of the Chit/CNT layer. The resistance $R_{\mathrm{ct}}$ describes the electron transfer kinetics of the redox probe at the electrode interface and its value is given by the semicircle diameter in the spectra.

The high-frequency region of the spectra, which represents the charge transfer and charge separation within the various types of Chit film, was analyzed in more detail. The values of $R_{\Omega}$ were slightly different for each type of film: $\sim 80$ (EDC-NHS), $\sim 85$ (GO), $\sim 100(\mathrm{ECH})$, and $\sim 115 \Omega \mathrm{cm}^{2}(\mathrm{GA})$. After modification with MWCNT, a small decrease in the $R_{\Omega}$ values was observed. These differences can be explained by the fact that each crosslinker forms a different film structure, which is also changed in the presence of MWCNTs in the film.

(29) Kang, X.; Mai, Z.; Zou, X.; Cai, P.; Mo, J. Talanta 2008, 74, 879-886.

(30) Liang, R.; Peng, H.; Qiu, J. J. Colloid Interface Sci. 2008, 320, 125-131.
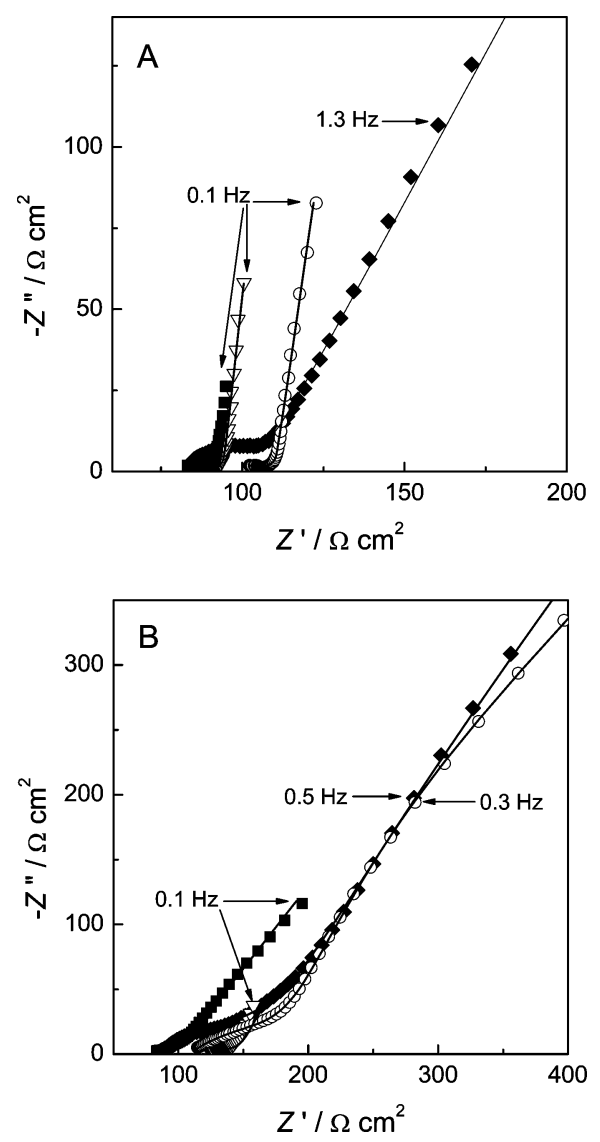

Figure 8. Complex plane impedance spectra of graphite composite electrodes with chitosan with $(A)$ and without carbon nanotubes $(B)$ with different cross-linkers $(\square)$ EDC; $(\diamond) \mathrm{GO} ;(\nabla) \mathrm{GA}$; (O) ECH. Lines show equivalent circuit fitting.

The values of the charge transfer resistance decreased to almost half with all cross-linkers when including nanotubes, as would be expected if the MWCNT cause an electrocatalytic effect. The capacitance values increased in all cases with the addition of carbon nanotubes, again showing easier electron transfer in the presence of MWCNT within the Chit-cross-linker modified films. The lowest charge transfer resistance values were obtained for ECH $\left(3.7 \Omega \mathrm{cm}^{2}\right)$ followed by EDC-NHS $\left(4.4 \Omega \mathrm{cm}^{2}\right)$, GA $\left(13.9 \Omega \mathrm{cm}^{2}\right)$, and finally GO $\left(35.4 \Omega \mathrm{cm}^{2}\right)$, suggesting that at ECH and EDC-NHS crosslinked MWCNT-Chit films the electron transfer is facilitated. Nevertheless, it should be remembered that the decrease of the observed charge transfer resistance is also partly caused by an increase of the total electroactive area after immobilization of carbon nanotubes on the surface of the graphite-epoxy composite electrode. This result is in agreement with cyclic voltammetry where the best cross-linkers were EDC-NHS and ECH: although the order of EDC-NHS and ECH is changed in the case of EIS, the values of the charge transfer resistance are very close to each other, so no clear distinction can be made as to which is better.

Response to Hydrogen Peroxide. Since hydrogen peroxide is usually a product of oxidase enzyme reactions, it is very important to evaluate the performance of the modified electrodes toward this compound if future use in enzyme biosensors is contemplated. Thus, the measurement of hydrogen peroxide at the four different types of electrode obtained by immobilization of carbon nanotubes into chitosan using different cross-linking agents were evaluated by cyclic voltammetry and fixed potential 


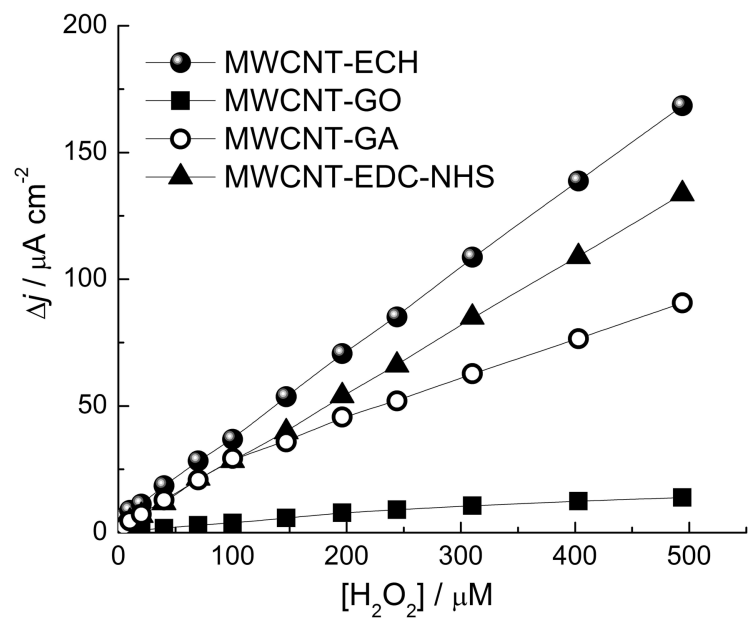

Figure 9. Hydrogen peroxide response at chitosan film electrodes with MWCNT and different cross-linkers. Applied potential $-0.1 \mathrm{~V}$ vs SCE in $0.1 \mathrm{M}$ phosphate buffer $\mathrm{pH}$ 7.0.

amperometry. The response to $\mathrm{H}_{2} \mathrm{O}_{2}$ starts at $+0.3 \mathrm{~V}$ for oxidation and at $-0.25 \mathrm{~V}$ vs SCE for reduction in the absence of nanotubes, the current increasing with increase in $\mathrm{H}_{2} \mathrm{O}_{2}$ concentration. With MWCNT in the film, reduction starts at $-0.05 \mathrm{~V}$, and oxidation commences at $+0.2 \mathrm{~V}$ vs SCE, showing the MWCNT electrocatalytic effect on the redox processes of hydrogen peroxide.

A good biosensor should be able to work at low potential values near $0.0 \mathrm{~V}$ in order to avoid interferences, so a potential of $-0.1 \mathrm{~V}$ vs SCE was chosen to perform fixed potential amperometric experiments. In all cases, an increase in cathodic current was observed indicating the reduction of hydrogen peroxide. Calibration curves for hydrogen peroxide with the four types of modified electrode over the same range of concentration are presented in Figure 9. The results show that the response, normalized to geometric area, was highest for the ECH-immobilized nanotubes. This electrode exhibited a linear response to hydrogen peroxide up to $500 \mu \mathrm{mol} \mathrm{L}^{-1}$ with sensitivity $332 \mathrm{nA} \mathrm{cm}^{-2} \mu \mathrm{M}^{-1}$; the detection limit (3 times the standard deviation of blank/slope of the analytical curve) was 6.0 $\mu \mathrm{M}$. The next best response was exhibited by the electrodes with nanotubes immobilized by GA but the linear range was significantly shorter, up to $100 \mu \mathrm{M}$. A slightly lower sensitivity was obtained at electrodes with nanotubes immobilized by EDC-NHS for which the linear range was similar to the case of $\mathrm{ECH}$, and the lowest sensitivity was found for GO-cross-linked MWCNTChit films, about ${ }^{1} /{ }_{10}$ th of the $\mathrm{ECH}$ response and a smaller linear range up to $200 \mu \mathrm{M}$, see Table 2 .

Unexpectedly, after normalizing to electroactive area (not shown), the lowest response was from electrodes with nanotubes immobilized by EDC-NHS. Even though their response was linear up to a higher concentration than GO and GA, similar to that of $\mathrm{ECH}$, the sensitivity at EDC-NHS-MWCNT was lower by a factor of about 12 than ECH-MWCNT.
Table 2. Analytical Parameters for Hydrogen Peroxide Determination at Carbon Nanotubes Immobilized into Chitosan with Different Crosslinkers, Normalized by Electrode Geometric Area

\begin{tabular}{lccc}
\multicolumn{1}{c}{$\begin{array}{c}\text { linear range/ } \\
\text { film composition }\end{array}$} & $\begin{array}{c}\text { sensitivity / } \\
\mathrm{nA} \mathrm{cm}\end{array}$ & $\begin{array}{c}\text { detection limit/ } \\
\mathrm{nA} \mathrm{M}^{-1}\end{array}$ & $\mu \mathrm{M}$ \\
Chit-GO-MWCNT & upto200 & $39 \pm 1$ & 8.8 \\
Chit-GA-MWCNT & upto100 & $278 \pm 4$ & 6.3 \\
Chit-ECH-MWCNT & upto500 & $332 \pm 1$ & 6.0 \\
Chit-EDC-NHS-MWCNT & upto500 & $267 \pm 2$ & 6.8 \\
\hline
\end{tabular}

\section{CONCLUSIONS}

Different cross-linkers, namely, glyoxal (GO), glutaraldehyde (GA), epichlorohydrin (ECH), and 1-ethyl-3-(3-dimethylaminopropyl) carbodiimide together with $N$-hydroxysuccinimide (EDCNHS) were evaluated for the immobilization of carbon nanotubes within a chitosan matrix. The nanotubes were immobilized using a graphite-epoxy resin composite as the base electrode. Electrodes with and without immobilized nanotubes were characterized by cyclic voltammetry and electrochemical impedance spectroscopy. By $\mathrm{CV}$, the highest peak current response in the presence of potassium hexacyanoferate(III) was obtained for EDCNHS immobilized nanotubes. The electroactive area was the highest in this case as well, followed by ECH and finally GO. EIS also showed that the charge transfer resistance decrease with inclusion of nanotubes, the electron transfer being fastest at the ECH-MWCNT electrode, followed by EDC-NHS-MWCNT.

Electrodes with immobilized nanotubes were applied successfully to the amperometric determination of hydrogen peroxide at potentials close to zero, and electrocatalytic effects were observed. These results are encouraging for the development of sensors and biosensors using carbon nanotubes immobilized by different cross-linkers.

\section{ACKNOWLEDGMENT}

Financial support from Fundação para a Ciência e a Tecnologia (FCT), Grants PTDC/QUI/65255/2006 and PTDC/QUI/65732/ 2006, POCI 2010 (cofinanced by the European Community Fund FEDER) and CEMUC (Research Unit 285), Portugal, is gratefully acknowledged. O.F.-F. thanks Grant CAPES/4383-07-9, UFSCar, and the University of Coimbra for a visiting professorship. R.P. and M.E.G. thank FCT for Postdoctoral Fellowships SFRH/BPD/ 27075/2006 and SFRH/BPD/36930/2007, respectively.

\section{NOTE ADDED AFTER ASAP PUBLICATION}

This manuscript originally posted ASAP on May 27, 2009. Figure 9 was replaced, and the corrected version posted ASAP May 29, 2009.

Received for review March 3, 2009. Accepted May 8, 2009.

AC900464Z 